\title{
5. The New Media and the Campaign
}

\author{
Peter John Chen
}

Over the past decade new media has moved from a marginal place in political campaigning in Australia to an integral element of the electoral strategies of political parties, candidates and some civil-society organisations. At the same time, the impact of these channels shifted from alternative avenues for political communication to intrinsic parts of coordinated and centralised multichannel message distribution. In examining the role of new media in the 2010 election, this chapter examines the adoption and use of a variety of new and increasingly entrenched new media channels in the political communication mix in Australia. Using Norris and others' notions of 'modern' and 'postmodern' campaign strategies, this chapter identifies the current practices of the major parties in Australia as sitting between these two forms of meta-strategy. This is informed by a focus on a limited set of key media channels in Australia as the primary focus of political parties' attempts to define campaign narratives and the resultant dominance of the marketing model of political communication in Australian campaigns.

The narrow news agenda in Australia is the result of comparatively close relationships between campaign communications strategies and mainstream media production practices. In the 2010 electoral cycle, this was countered to some extent by a small number of civil-society actors who challenged media hegemony through deconstruction of contemporary media practice, as well as by new forms of political mobilisation led by the emerging third-party group GetUp!. To examine the place of new media in the 2010 election, this chapter looks at the media strategies of key actors: political parties and candidates, non-party organisations and alternative media (bloggers and micro-bloggers). Before we can discuss these actors, however, it is necessary to situate new media within its wider communication landscape. We see established and new media positioned within a complex media ecosystem of channels, actors and institutions that are bound together by competition, intersecting audiences, power relationships and inter-media agenda setting.

\section{The Media Context for the Election}

It is important to consider the role of new media in context. Elsewhere (see Chen 2010; Chen and Vromen 2010), we have established that an increasing amount of political content was consumed online compared with previous elections, and 
the consumption of political content increased during the electoral period (from circa 7 to 15 per cent of pages viewed). While this speaks to an increasing role for online media in electoral politics, we have also identified that the majority of this content is sourced from established commercial and public media channels (these factors are illustrated in Figure 5.1). Thus, while minor parties such as the Australian Greens might be encouraged by their comparatively high traffic rates given their voter share (Figure 5.2), this represents a tiny fraction of online content consumption overall.

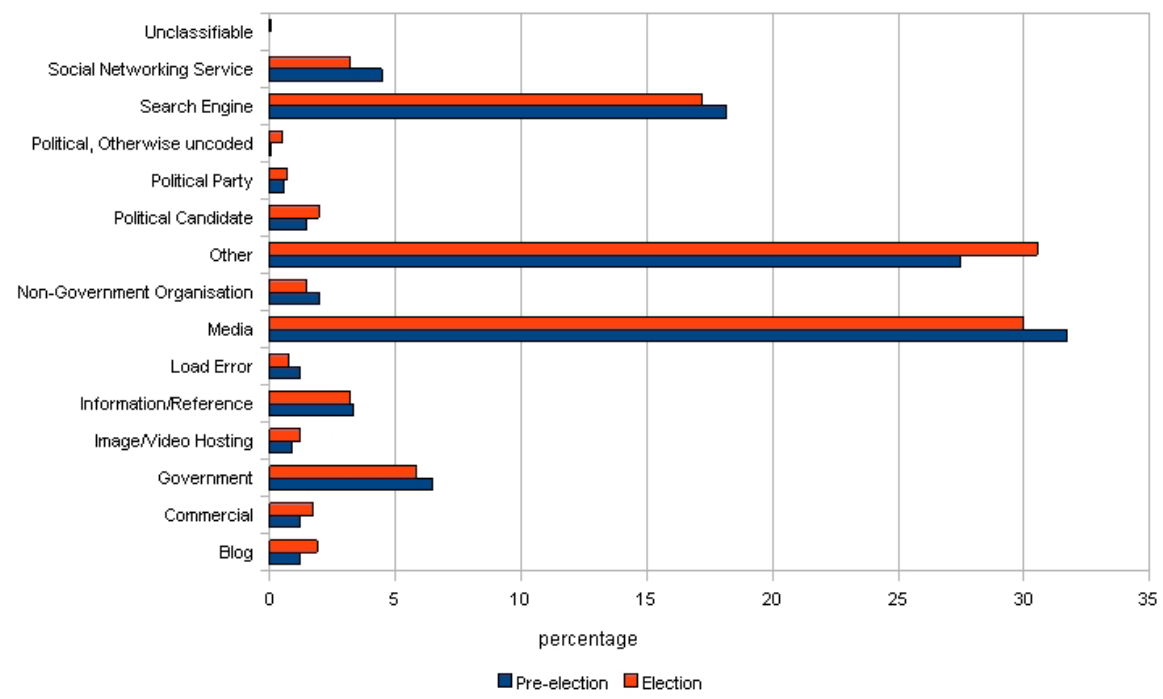

Figure 5.1 Average Users' Page Visits, Pre-Election and Election Period Compared

Source: Based on a panel study of Australian Internet users who were intending to vote in the 2010 election.

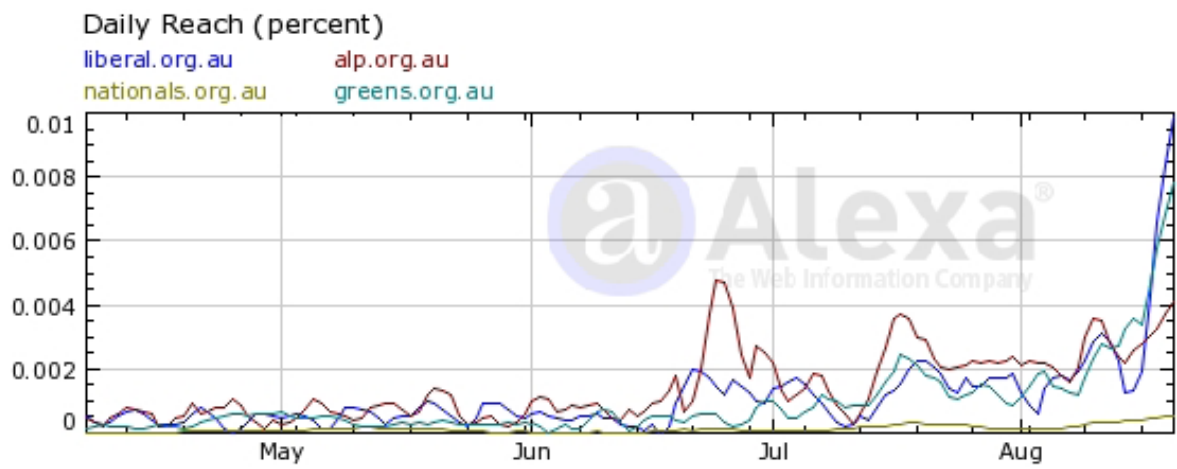

Figure 5.2 Web Traffic to Political Party Web Sites, April-August 2010

Source: Compiled from Alexa. 
While this would speak to the 'normalisation' of new media's impact on politics (reversion to status quo and cooption by existing elites; Small 2008), the altering political economy of online news has seen a narrowing of political coverage online, with Goot $(2008,99)$ observing a greater bias towards coverage of the Government over Opposition or minor parties. Thus, while new media was expected to break free of hegemonic news agendas, the declining resource base for news construction online seems to have had the opposite effect overall. What we find interesting about the 2010 election, however, is not the prospect of mass conversion through online channels, but the relationship between new media and agenda-setting processes of control and resistance.

\section{Insiders and the Battle for the Narrative}

The Australian election in 2010 was interesting because of the comparatively small range of key themes and policies that consumed the campaign. While key policy topics are discussed in detail elsewhere in this volume, the political communication perspective leads to a focus on three meta-narratives that came to dominate coverage of the campaign and the immediate preceding period. These meta-narratives were: the 'horserace', illustrated in obsessive coverage of comparatively meaningless polling data (given the margin of error in close electoral contexts); the imposition of artificial relationship stories between key political actors (for example, Gillard-Abbott's 'flirting'; AAP 2009); and the engineering and disruption of pseudo-events, such as the insertion of Mark Latham into the election campaign as both an object of easy ridicule and a means of derailing planned campaign events (Esser and Spanier 2005).

The persistence of these meta-narratives is the result of situational and structural factors. While the comparatively late leadership change within the ALP was always likely to be a key story during the election given its novelty, gender clearly played a role in the fascination of political commentators with the relationship between Julia Gillard and Kevin Rudd. Unlike in the ascendency of Tony Abbott, here, a feminised role was projected on Julia Gillard through media frames that placed the emphasis on relationship repair (the quest for her apology; AAP 2010) and maintenance (Rudd's rehabilitation into the Cabinet) as obligations she had to meet - a narrative turn associated with an uncritical acceptance of Opposition and media claims of her unopposed election to leadership as somehow illegitimate due to the projection of presidentialism on the election of Kevin Rudd in 2007 (but more likely due to her gender). Structurally, the known length of the campaign and daily media packages provided by campaign teams have driven the focus on horserace reporting, with the resultant tendency to shift substantive coverage from policy topics 
into deconstruction of campaign strategies and the circular assessment by the media of campaign performance based on media performance and the capacity of candidates to 'win' each day's (or hour's) news cycle (Mutz 1995). ${ }^{1}$

None of the parties was able to break out of the constraints of these meta-narratives during the campaign, regardless of clear attempts by the Prime Minister to 'reboot' her campaign during the second week. This tends to demonstrate a number of factors about the Australian media ecosystem, but also about the way parties have responded to it. Overall, I argue that the political strategy of the major political parties can be seen to remain within the 'modern' paradigm identified by Norris (2000, 138): centralisation and emphasis on mass media, with largely undifferentiated messaging. This appears to be over-determined by the corresponding characteristics of media in Australia: its small number of major media channels, the tendency for increasing reliance on syndicated content, and the resulting narrowing of the media agendas reported across the country. The implications for this are both a loss of agenda-setting capacity to the media and a narrowing of the range of subject and depth likely to appear in political reporting.

\section{Targeted Use of New Media}

What is interesting is the extent to which parties were able and willing to move outside this model of communication. In this regard, there appears to be mixed results. On the one hand, it is clear that there are signs Lees-Marshment's (2001) marketing model has gained traction through the use of specialist consultancies and market research in shaping messages and campaign strategies. This picks up on the professionalisation approach developed in the United Kingdom during the 1990s (Gould 1999) to substitute for declining internal party resources. On the other hand, attempts to segment the marketplace and engage in diverse messaging strategies aimed at specific segments were considerably less successful.

Thus, while the Liberals largely 'went wide' with the three 'nos' (no to debt, boats and waste), the ALP employed the so-called 'small-bore' strategy pioneered by the Clinton campaign in the United States (Lowry 2003) and engaged in the cooption of policies associated with the Coalition, such as Internet filtering (Counihan 2010) and immigration policy. Without the extensive fragmentation seen in the United States through local media and particularly cable news channels, this failed to be effective. Targeted policy announcements ideal to this strategy were quickly coopted into national stories in the Australian media context; the use of the marketing approach itself was seen as a takeover of the

1 And increasingly the 'new-media' cycle, particularly given the ability of journalists to harvest numbers (followers, posts, and so on) from web sites. A good example of this is Guselli (2010). 
federal ALP by the 'NSW disease', while issues focused on unrest in neglected areas of Sydney (such as rail announcements) were magnified into national stories. This was problematic given that their strategy relies on selective attention because of the inherent trade-off associated with the mass-party model it supports.

Here we see a weakness of Australia's increasingly cartelist party system. ${ }^{2}$ Unable or unwilling to draw upon a wide range of policies initiated by the former leader during the election campaign, the ALP could not benefit from the advantages of incumbency. Under different circumstances, the Government would have entered the election with major advertising campaigns supporting both carbon trading and mining tax reform, bolstering their transition from government into the electoral process. In 2010, this was missing, providing a space for mining industry concerns and interventionist media to fill. In addition, neither party managed to fully capitalise on the online communities developed during previous elections. Thus, while previous leaders such as Rudd and Malcolm Turnbull had built up large numbers of followers on their various social networking services (SNS), their cultivation and use between elections were limited. This differs from the mobilisation of supporters undertaken by the administration of Barack Obama as a continuance of campaigning into government over key policy issues, which helps to sustain support networks developed during the campaign but also demonstrates that Australia's permanent campaign is more rhetorical than demonstrative. The tendency for campaign teams to mobilise late and demobilise quickly after elections undermines the community development value of these channels. That politics is increasingly mediatised is clear, but that is not the same as maintaining a constant campaign approach to all political communication.

This is not to say that segmentation and micro-channelling of messages were not employed in the campaign, but their capacity to realise significant benefits was limited. The most clear use of these types of new-media targeting was largely in the parody tactics employed by the ALP against Tony Abbott, including the establishment of the 'Phoney Tony' fake Twitter account (Kwek 2010a) - reusing the established online meme of parodying public figures on SNS - and the use of a customised billboard web site originally used in the 2010 UK general election. Figure 5.3 illustrates an example of the latter, which illustrate the connection between personal parody and policy criticism (in these examples, criticising Abbott's inability to articulate technical issues about the Coalition's alternative broadband policy). Other tactical approaches to market segmentation were less visible: the Australian Greens made a limited attempt to

2 Incumbency, however, still provides considerable advantages. In the case of new media, incumbency is positively associated with having a web site (0.39) and SNS $(0.28)$. 
mobilise voter enrolment through the use of a targeted YouTube video by Sarah Hanson-Young ${ }^{3}$ - an approach dramatically overshadowed by GetUp!'s election trailer video.

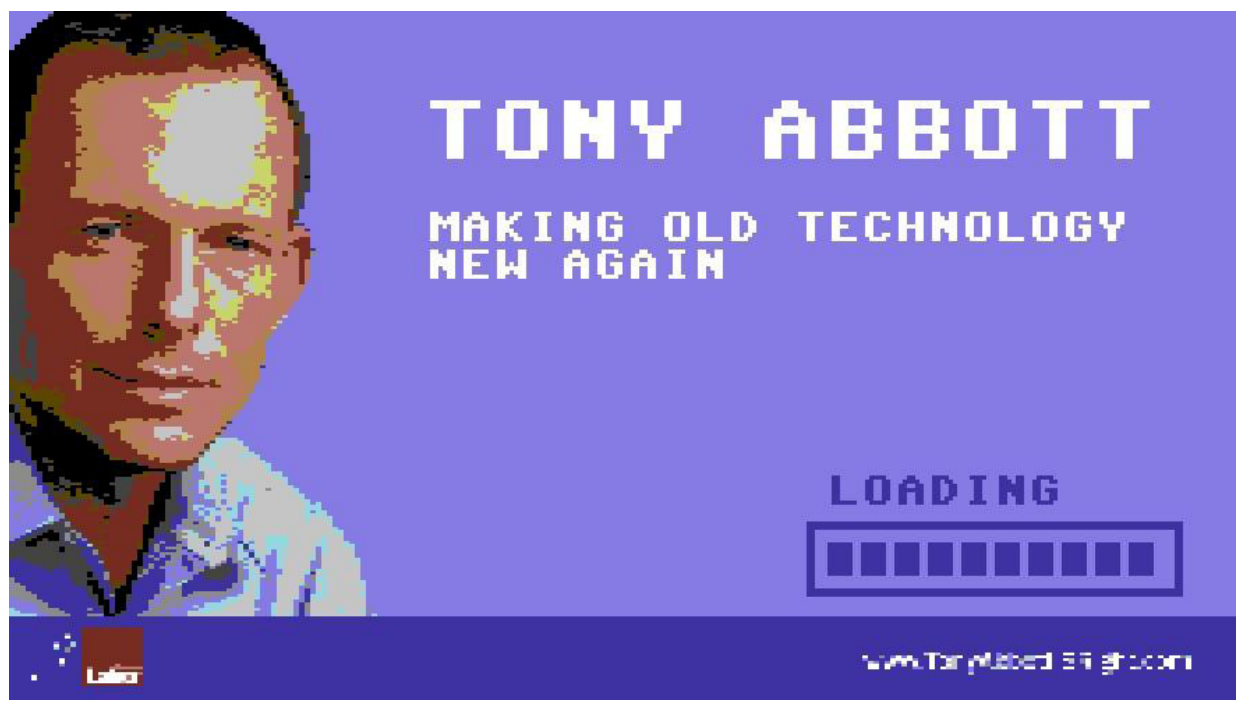

Figure 5.3 Parody Billboards Posted at <www.tonyabbottisright.com >

\section{Diversification in the Use of New Media}

In examining the use of new media by candidates, we can identify that there are moves to shift campaigning from the mass model of modernism into a more postmodern style. This, Norris observes, employs overarching strategy with coordinated localism, allowing for message customisation at the local level. The Liberal Party, as an example, employed this in terms of television advertising at the lowest level of granularity for TV ad buying: using custom advertisements in Western Australia. They were also observed using Google AdWords to target key electorate searches (Howden 2010) - a tool that is much more surgical than mass media, but also requires a greater investment in human resources (time, decision making) for smaller audience yields.

3 'Don't waste your first time' - an entertaining spoof of the well-publicised advice of Tony Abbott to his daughters regarding their virginity $(<\mathrm{http}$ ://sarah-hanson-young.greensmps.org.au/content/dont-wasteyour-first-time $>$ ). 
What is interesting is that the use of new media by candidates has considerably diversified over the years. This runs counter to our previous hypothesis (Chen and Walsh 2009) that greater provision of templated web sites and social networking profiles by parties would homogenise the representation of candidates online. This is illustrated in Figures 5.4 and 5.5. ${ }^{4}$ The first illustrates the adoption of a range of new media channels by candidates in the 2010 election. What this shows is that there is considerable difference between the adoption of different channels between major parties (the ALP and Coalition) and minor parties, but that emerging minor parties (the Greens) appear to make up for areas of underrepresentation (web sites) with alternative channels (SNS) - a substitution effect previously observed. Importantly, Figure 5.5 (a compound figure that illustrates the visibility of candidates online based on the depth of content provided and the width of visible points of presence through multi-channelling) demonstrates the greater diversity of online performance in 2010 than in 2007. As a small number of key performers in all the three parties listed have dramatically increased their use of online media, this has shifted the average performance downwards on these relative scales.

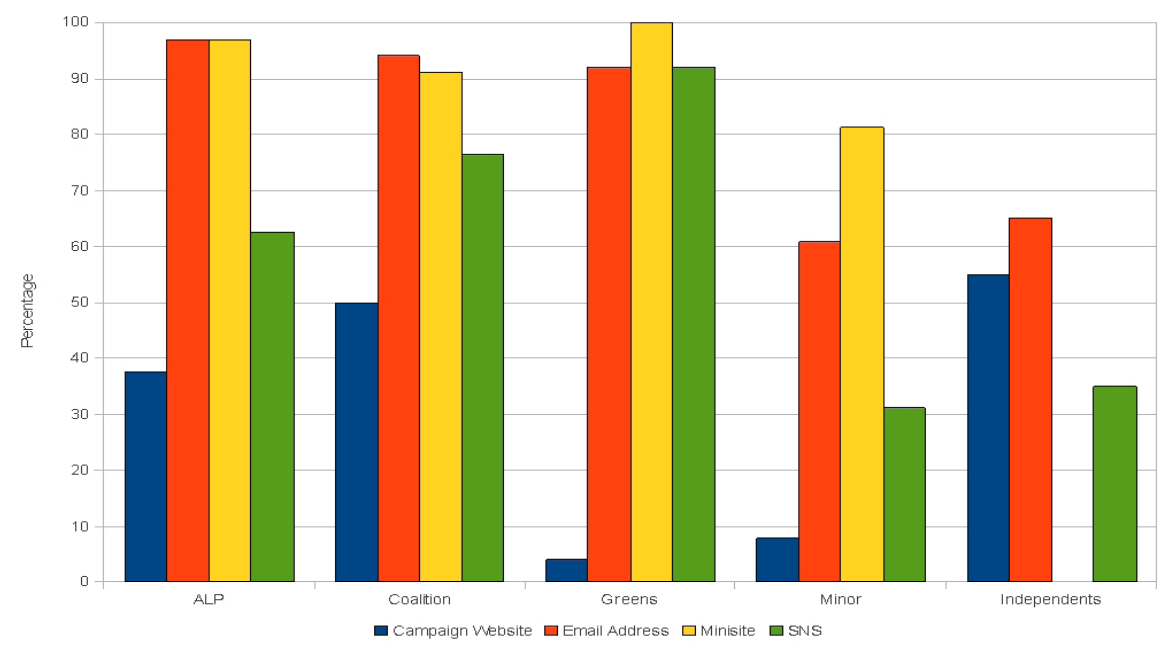

Figure 5.4 Candidates' Use of Online Communication Channels

4 These figures are based on the content analysis of 175 candidates. 


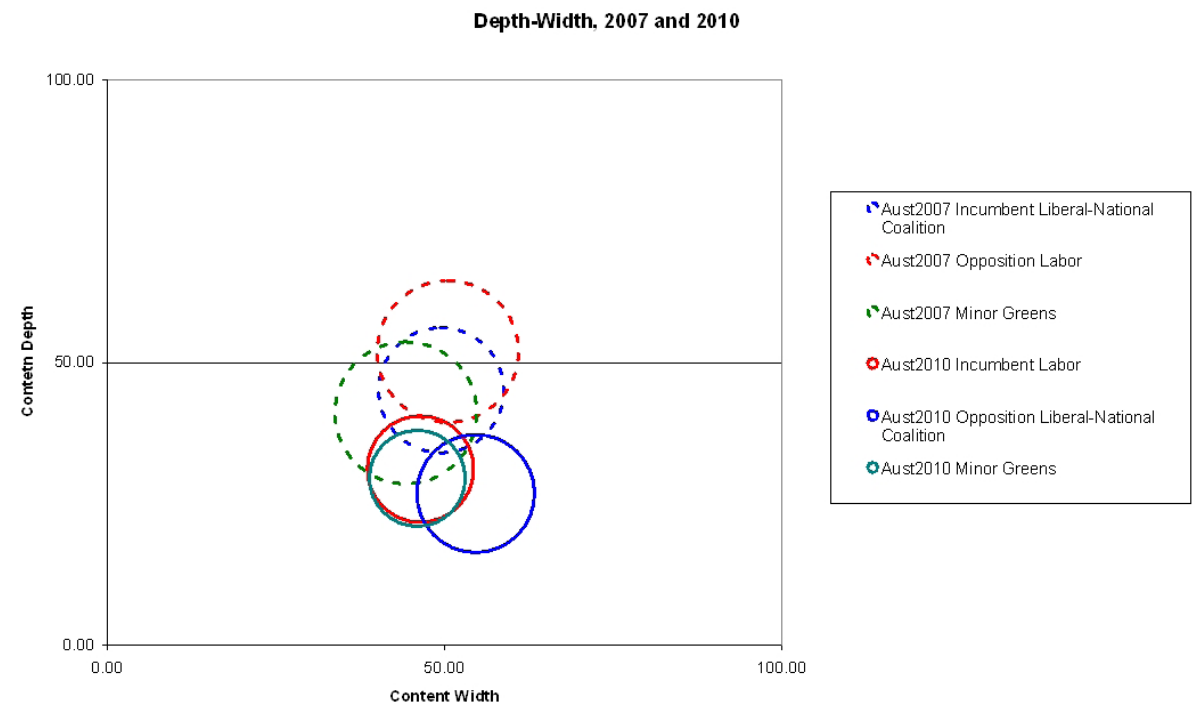

Figure 5.5 Candidates' Points of Presence Online: Clustered by party, 2007 and 2010

\section{Equalisation and the Social Media Effect}

Our assessment of previous elections has tended to follow Small's (2008) assessment of the Canadian experience: equalisation of access by minor parties without noticeable impact on their electoral performance. In one way, the discussion above demonstrates this to be the case in the 2010 election: regardless of the ability to present competitive online content, minor parties have entrenched disadvantages in the two-party system of Australia. This can be demonstrated better by looking at party systems, such as reports of major-party candidates developing the content of party databases using data mining and the freedom of information (FOI) requests of local government (Novak and Kenny 2010). While the Greens deployed new electoral-management technology in the lead-up to the 2010 election to increase their electoral intelligence, they were unable to make full use of this system due to issues of local training and capacity. This appears to reiterate previous findings from survey data that showed minor parties were far less likely to capture data into electoral-roll database systems during the campaign (Chen 2005); however, the building of capacity within the party, combined with the financial windfall associated with their strong result in 2010, could see this turn around in the next electoral cycle. 
Additionally, it is not clear that internal capacity was as important as it has been in previous elections. A good example of this is the use of social networking systems within the party web sites - a practice undertaken in this election by the ALP (Campaign iQ) and Liberal (my Liberal) parties. This clearly follows the model used in the United States by the Obama presidential campaign: deliberate use of social networking (CeBIT 2010), but a focus on drawing communities into a domain controlled by the candidate, which provides greater control over what occurs, ${ }^{5}$ but also better information about user behaviour for the purposes of mining information about participants. The success of this model in the Australian context, however, appears modest at best. As illustrated in Table 5.1, participation in these online forums was quite modest, and it is questionable whether the short time frame of the Australian electoral cycle is the best place to build these communities. Interestingly, in the case of the ALP, there appears to be no consistent plan to employ this platform post election, with the ALP's post-election review process using a separate submission system for members to submit feedback and input to the party, rather than the more interactive discussion forums established in Campaign iQ.

Table 5.1 Party Web Site Voter Engagement Performance

\begin{tabular}{|c|c|c|c|c|c|c|c|}
\hline \multirow[b]{2}{*}{ Party } & \multirow[b]{2}{*}{ Indicator } & \multicolumn{6}{|c|}{ Week ending } \\
\hline & & 21 July & 28 July & 4 August & 11 August & 18 August & 25 August \\
\hline \multirow[t]{5}{*}{ ALP } & Members & 963 & 1325 & 1723 & 2073 & 2323 & 2608 \\
\hline & Groups & 30 & 35 & 39 & 47 & 47 & 47 \\
\hline & Issues & 2 & 2 & 2 & 2 & 2 & 2 \\
\hline & Ideas & 60 & 101 & 162 & 238 & 267 & 287 \\
\hline & Comments & 63 & 115 & 161 & 220 & 264 & 288 \\
\hline \multirow[t]{2}{*}{ Liberal } & Ideas & 23 & 26 & 47 & 54 & 55 & 55 \\
\hline & Comments & 209 & 400 & 550 & 737 & 804 & 854 \\
\hline
\end{tabular}

Sources: Compiled from <www.alp.org.au >; <www.liberal.org.au >; <http://www.formspring.me/GreensMPs >

The capacity to draw supporters into your own social networking community requires considerable planning and incentives, which the Australian environment does not appear to provide. This meant that general SNS had greater appeal for members of the public who were more likely to use them as creative vehicles for political expression (see below) but also conventional political engagement. In this context, incumbency was less important than social capital, with the Greens able to exploit their comparatively younger audience to have greater traction through tools such as Twitter. Grant et al. (2010) identify presidentialism in services such as Twitter, which we discuss below; they also argue that the higher

5 It should be noted, however, that there appeared to be lower levels of message vetting on these systems than in previous years, with negative and critical messages allowed to stay up during the election campaign. 
'conversational' nature of Greens politicians on this service leads to enhanced success and visibility for this group overall, which points to the increased potential for postmodern campaigning.

The shift away from static information repositories (Figure 5.6) has other implications for candidates' and parties' political communication. The narrative construction of the messages communicated through SNS (through successive chronological posts and RSS feeds) might serve to lock political actors more closely into the temporal flow of the campaign. While web sites have previously been criticised because of their static content and brochure-ware characteristics (for example, Gibson and Ward 2002), this is evidence of the way political actors will sometimes attempt to compress time - to capture key images and messages they wish to highlight and reiterate to audiences (Sanders 2009). While time compression can be misleading and distort the portrayal of events (indeed, it is the core aim of most political stunts and pseudo-events), it is a key means by which the relentless flow of news-cycle immediacy can be interrupted. Becoming embedded in a channel with a high rate of message decay both allows for adherence to the rapid response model of agenda management ${ }^{6}$ and places weaker political actors into a subordinate position to major-media news issues of the day. This has considerable implications for power relations ${ }^{7}$ within the Australian media ecosystem, which require further exploration.

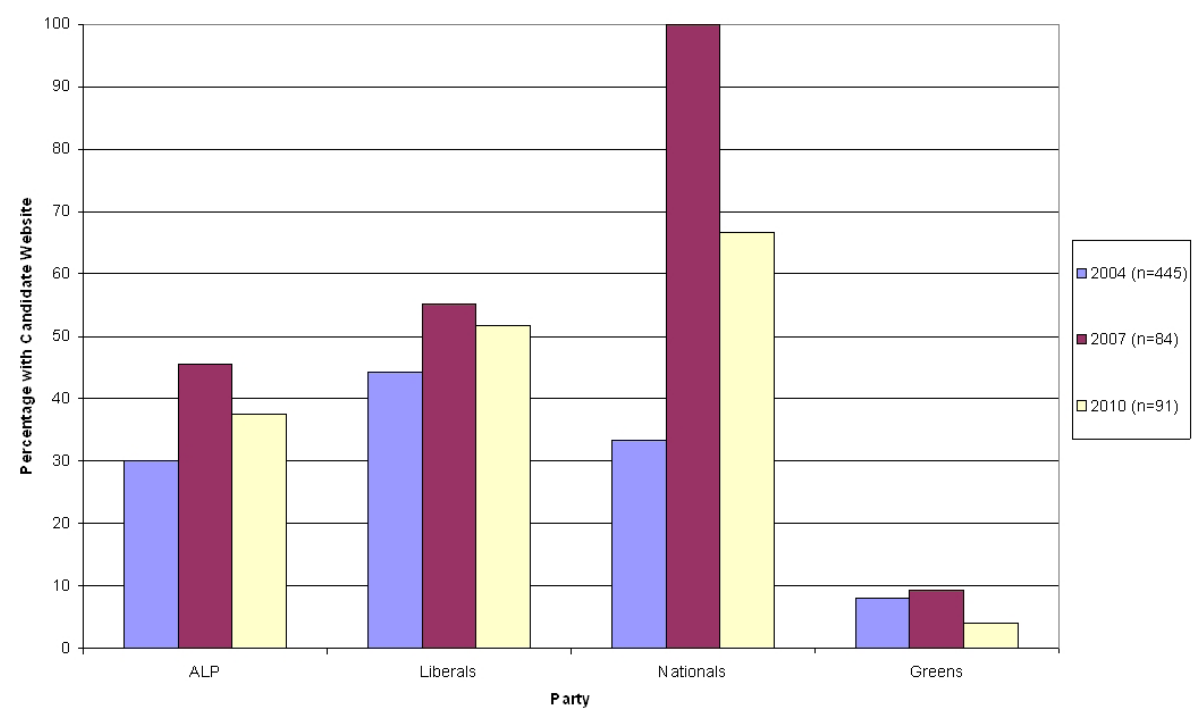

Figure 5.6 Candidates' Use of Personal Campaign Web Sites, 2004-10 by party

6 Additionally, digital video production and online distribution allowed services such as YouTube to be more important in the construction and distribution of quick-response ads and short videos (Gordon 2010).

7 For example, some politicians are using SMS and SNS messaging to enhance their source value (and influence) to journalists who are increasingly subject to the professional need for quick news production and instantaneous reporting (Meade 2010). 


\section{The Outsiders}

Candidate-centric communication and journalist-source relations - while still critical in terms of the majority of online political content consumed-are increasingly challenged by outsiders. At the basic level, the rise of online media has undermined existing business models for news production and distribution, leading to the strengthening of a more limited range of meta-narratives, as previously discussed. On the other hand, new-media entrants have arisen that are increasingly interesting in terms of their ability to shape media agendas and mobilise political resources. These two political actors are seen in the rise of a new form of cultural production (gatewatching) and the virtualisation of interest groups and third-party political actors.

\section{Gatewatchers}

Bruns (2003) sees 'gatewatchers' as an emerging group of online content producers who observe, validate and criticise information produced by existing media organisations. He argues that due to the changing economics of information distribution, the privileged position the media channels to control access to information has been reduced through an increasing decline in scarcity. The implications of this are important: seeing the rise of new forms of content production (blogs, micro-blogs), new communities of interest (often gathered around specific interest areas that aggregate diverse content that might not have been economically feasible previously) and new forms of sociability.

The extent to which this dramatically alters the logic of political competition and performance is unclear. On one hand, it is possible to see the somewhat parasitic nature of some of these communities and channels as leading to an increased dependence on established content producers. This is visible in the tendency of SNS to be a virtuous circle for media and political celebrities. This was clear in the 2010 election when key political figures (leaders, but also individuals who remained strongly in the media spotlight as bitter ex-leaders) received considerable attention (both in terms of 'friendship' ties and as the subject of discussion). Figures 5.7, 5.8 and 5.9 illustrate this well: key figures receiving strong mainstream-media coverage benefit disproportionately in terms of online buzz. This reflects a tendency towards magnification of visibility online rather than diversity, which Hindman et al. (2003) refer to as the 'googlearchy' - a tendency also seen in Twitter coverage of election pseudo-events (Bourke 2010). 
Twitter Followers (Sans Kevin Rudd)

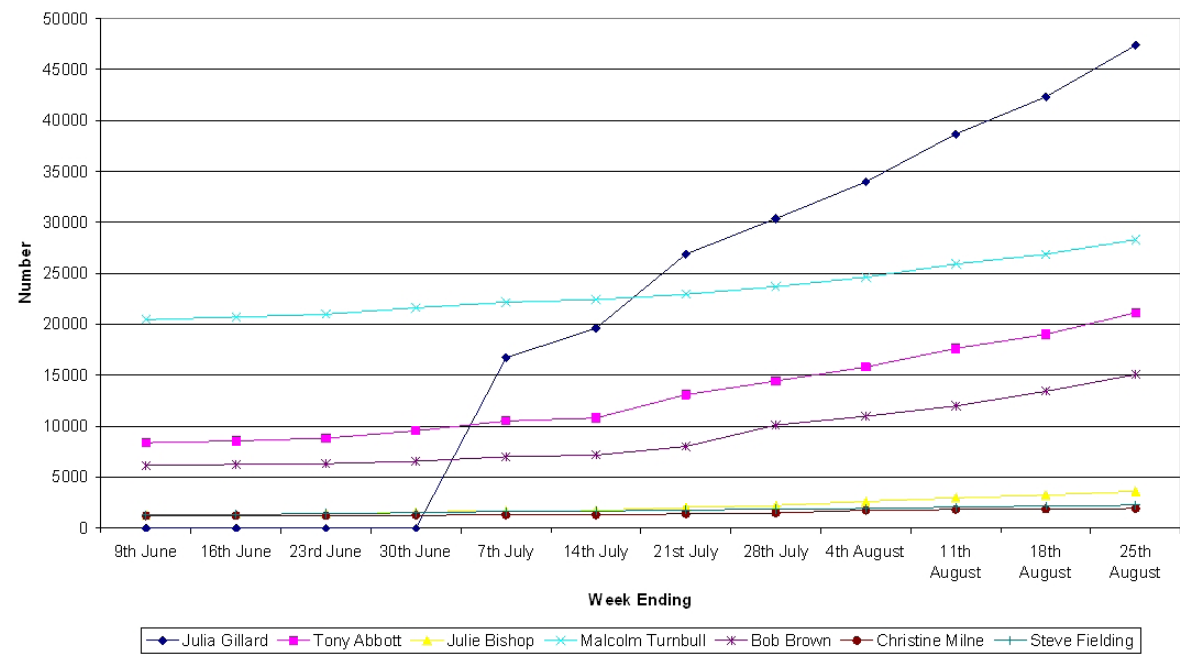

Figure 5.7 Party Leaders' Twitter Followers, June-August 2010

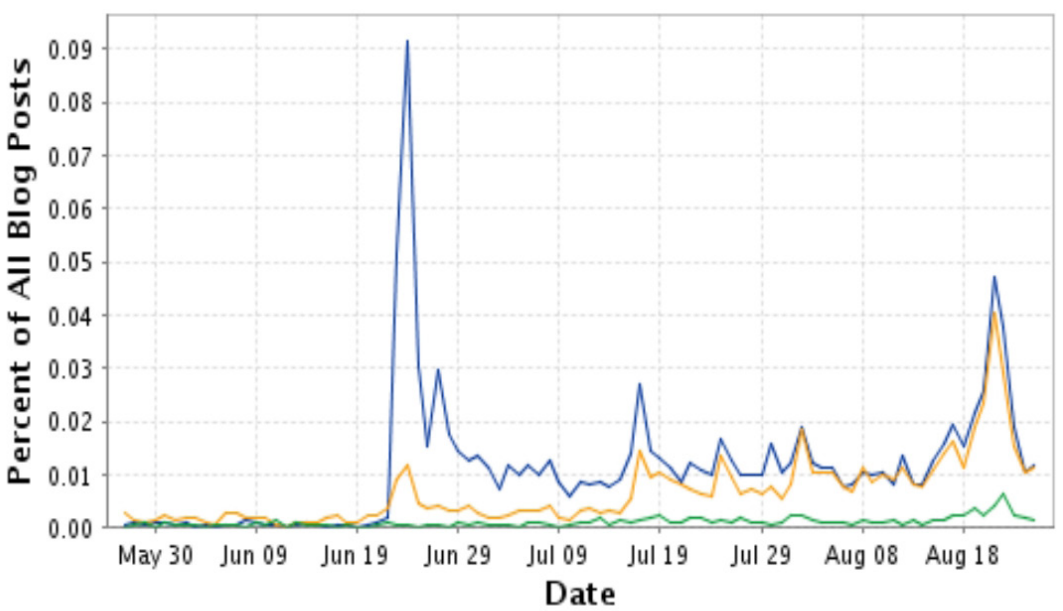

Julia Gillard $\mathbf{a}$ Tony Abbott Bob Brown

Figure 5.8 Comparative Attention Paid to Leaders in Blog Posts, May-August 2010 


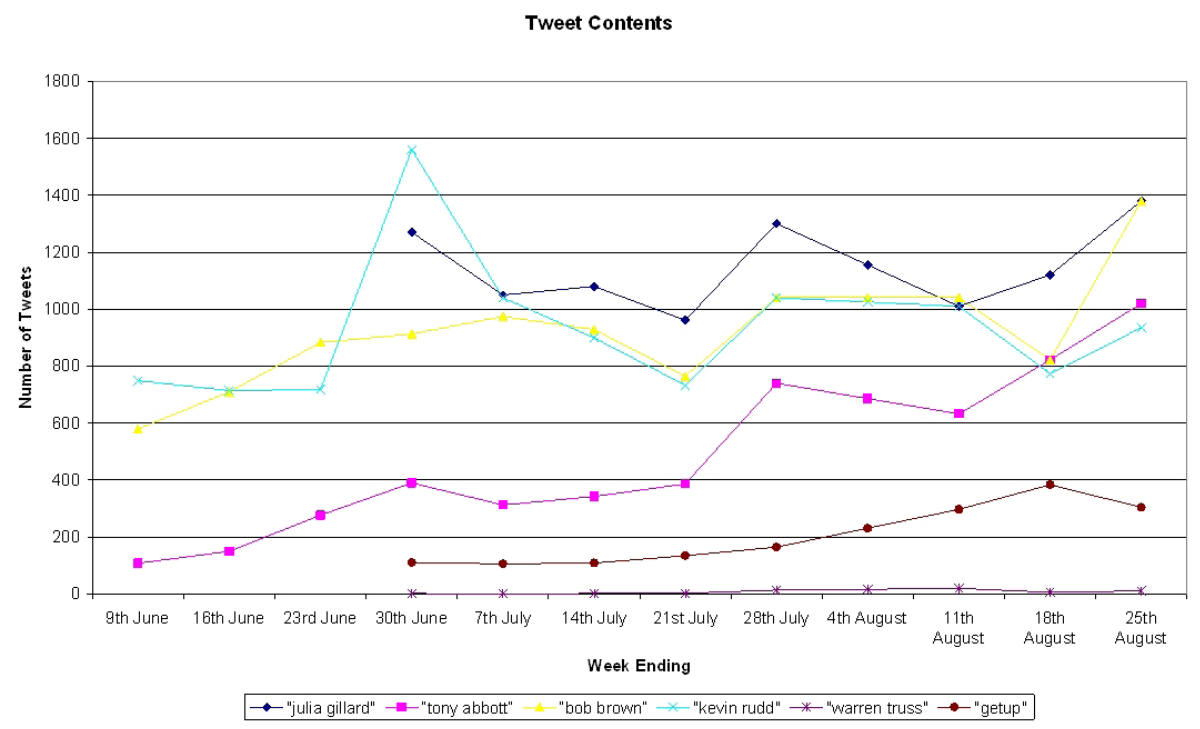

Figure 5.9 Content of Tweets Posted, June-August 2010

Source: Compiled from Tweet Volume.

Mass coverage is, however, only one aspect of this story and we have to recognise the growing importance of these forms of alternative media as scrutineers of journalistic practice (Cahill and Ward 2007). In the 2007 election this was seen in technical discussion of the use and interpretation of polling data in mainstream media (Flew 2008). Here the flipside of time-compression impacts is important. While we previously observed that this can make weaker actors subordinate to dominant narratives, services such as Twitter do allow time-compressed events to be unpacked. This was clearly the case in the relationship between Twitterenabled audiences and key political pseudo-events.

While the integration (direct or indirect) of Twitter into campaign set-piece events generally fed into established meta-narratives (particularly an obsession with trivial issues, such as leaders' appearance; Buchanan and Elliott 2010), at times the online audiences were able to unpack mainstream-media claims about these events as legitimate places of public opinion formation, such as the identification of the son of a Liberal MP in the Rooty Hill leaders' debate (Kwek 2010b). This is significant in that the power of pseudo-events lies in the essential collaboration between politicians and journalists in the creation of reality and the suppression of its underlying artifice.

Audience deconstruction was a key area of gatewatching in the 2010 election, with a minor celebrity identified as a questioner in the $\mathrm{ABC}^{\prime} \mathrm{s} Q \& A$, but also a degree of self-reflection about the very limited socioeconomic diversity among 
the gatewatchers themselves (Wilson 2010). In the post-election period, this has led to some tensions between established and online media, with journalists beginning to question and challenge the cultural norms of bloggers seen to be increasingly influential in shaping media coverage of electoral politics (Jericho 2010).

\section{Emergent Models of Activism}

The changing function of political parties and the resultant (or causal) impacts on political socialisation have undermined traditional means of defining political participation while generating new forms of activism. In the 2010 election, we can see that the expanding use of SNS within the community has opened new avenues for 'micro-activism', while the progressive advocacy group GetUp! had considerable success in mobilising resources in support of policies most clearly associated with the Australian Greens.

In previous elections, we have seen the use of parody web sites (Chen 2005) and videos as important vehicles for non-party political expression (Chen 2008). This online content has commonly taken the form of parodies of party leaders and signature policies. In doing so, they have tended to advocate, directly or indirectly, in favour of alternative voting decisions (a good example of the former would be <www.marklathamsucks.com $>$ and of the latter would be the 'Johnny Overboard' web sites of the 2004 election). Over the past two election cycles in Australia these web sites have been in decline, as creative energy has shifted towards the more easily established and promoted use of groups on SNS. Examples such as 'Friends don't let friends vote for Tony Abbott' and 'That awkward moment when Julia Gillard takes your job' illustrate these types of group: each presents a specific party or party leaders (conservatism, disloyalty) while explicitly calling for votes against their respective parties.

Interestingly, while this form of campaigning has largely been discounted as low-engagement 'slactivism' (weak political engagement that demonstrates cynicism), Marichal (2010) argues that these channels of communication should be considered more carefully because of their increasing cultural pervasiveness, but also because of their capacity to provide a space for dialogue competing with and crosscutting political positions. This was previously observed in the use of online discussion forums behind 'Mark Latham Sucks', which presented a much more dynamic space for interaction than its (or its successors') name would suggest.

Even the comparatively non-directive version of these types of online expression (such as the women who changed their Facebook status to 'Julia' in celebration of the elevation of the first woman to the prime ministership; Tovey 
2010) can be seen as interesting in the way this substitutes for other forms of political expression and alignment not generally seen in Australia (such as lawn signs, political discussions, or pins). These thus replace older forms of political expression, sustain social movement cultures, and import more public forms of political identity expression (or at least the public-private world of SNS).

More formally, the changing nature of advocacy politics saw the dramatic expansion of the influence of the left-wing group GetUp! in the 2010 campaign. Occupying a similar role to that of the 'Your Rights At Work' campaign from 2007, GetUp! aggregated membership donations and union funding towards a broad set of initiatives in the lead-up to and during the campaign. The media influence of the group is impressive - as illustrated in Table 5.2-pulling a far greater share of views to its video material than any of the political parties (largely due to the spoof movie trailer aimed at encouraging younger people to enrol to vote) ${ }^{8}$ or the ABC's specific election parody YouTube channel. GetUp! is able to turn this online visibility into mainstream media visibility through targeted fundraising to take online advertisements onto commercial election coverage (Vromen 2008).

This demonstrates that virtualised interest groups of the model promoted by MoveOn.org in the United States have the potential to be effective in mobilising political resources outside that nation. Overall, this benefited the Greens most of all-highlighting issues most favourable to them, enrolling voters most likely to vote for them, and actively endorsing the Greens through their policy check list - an unsurprising outcome given the over-representation of Greens voters (Marks 2010) in the membership of the organisation. ${ }^{9}$

Table 5.2 YouTube Videos Posted Within 50 Days of the Election Date, 2010

\begin{tabular}{|c|c|c|c|c|c|c|}
\hline & & ALP & Liberal & Greens & GetUp! & $\begin{array}{l}\text { ABC's } \\
\text { 'Sledge' }\end{array}$ \\
\hline \multirow{3}{*}{2010} & Views & 256279 & 290444 & 84290 & 549244 & 16319 \\
\hline & Videos & 59 & 22 & 19 & 8 & 8 \\
\hline & Average views & 4344 & 13202 & 4436 & 68656 & 2040 \\
\hline \multirow{3}{*}{2007} & Views & 160896 & 150719 & 36686 & \multirow{3}{*}{\multicolumn{2}{|c|}{ Not collected in 2007}} \\
\hline & Videos & 14 & 25 & 14 & & \\
\hline & Average views & 11493 & 6029 & 2620 & & \\
\hline
\end{tabular}

Source: Compiled from YouTube.

We have to recognise, however, that the ability of political parties to capture public resources remains a significant counterweight to the comparatively

8 'Election 2010 Spoof Trailer-GetUp': <http://www.youtube.com/watch?v=Qub4lWT6GNk>

9 In the lead-up to the election, GetUp! surveyed members to determine its policy position for the campaign, leading to this somewhat circular outcome. 
modest budget of GetUp!. The ability of GetUp! to be effective outside its media niche is therefore questionable. Offline, the organisation has had its biggest victories (both directly and through the resultant exposure it gained) through litigation - a unique opportunity that is not easy to reproduce. The organisation's experience with mobilising members physically was mixed. As Table 5.3 demonstrates, election planning meet-ups were only modestly subscribed and the small organisation's ability to organise at the local level remained modest (Griffiths 2010). In future, the organisation is likely to shift back to a model that focuses on partnerships with other organisations that bring local resources (such as the capacity for offline mobilisation), rather than continue to expand into the type of organisational complexity more associated with parties.

Table 5.3 GetUp! Pre-Election Meet-Ups: Distribution and estimated attendance

\begin{tabular}{|l|c|c|c|c|}
\hline Jurisdiction & Number & $\begin{array}{c}\text { Percentage of } \\
\text { total }\end{array}$ & Not fully RSVPd & Fully RSVPd \\
\hline NT & 4 & 2.040 & 75 & 25 \\
\hline NSW/ACT & 56 & 28.57 & 76.78 & 23.21 \\
\hline Victoria & 62 & 31.63 & 61.29 & 38.70 \\
\hline SA & 12 & 6.12 & 25 & 75 \\
\hline WA & 26 & 13.26 & 73.07 & 26.92 \\
\hline Tasmania & 4 & 2.04 & 100 & 0 \\
\hline Queensland & 32 & 16.32 & 78.12 & 21.87 \\
\hline Total & 196 & 100 & & \\
\hline
\end{tabular}

\section{Conclusion}

Overall this chapter has presented a mixed picture of the role of new media in the 2010 election. For parties and candidates, new media has become an established, if not major, element of their marketing strategies. If Australia had structural characteristics more likely to encourage postmodern styles of campaigning, the current professionalism and platforms adopted within the major parties would provide for a more engaged and interesting set of campaigning strategies around market segmentation and local engagement. There is evidence that the major parties continue to experiment with these approaches, which indicates the strong influence of both UK and US campaigning approaches on the major parties. There remains, however, a tendency for media contraction towards a more limited set of policy topics, celebrity political actors and meta-narratives - a function of new media's impact on news production. This is countered to a limited degree by emerging civil-society organisations and citizen journalism, gatewatching and micro-activism, which have interesting potential to resist established ecosystem agenda-setting tendencies. 


\section{References}

Australian Associated Press (AAP). 2009. 'No more flirting, Abbott tells Gillard'. Sydney Morning Herald, 1 December, viewed 30 September 2010, <http:// www.smh.com.au/national/no-more-flirting-abbott-tells-gillard-20091201k2ue.html>

Australian Associated Press (AAP). 2010. 'Gillard and Rudd won't campaign alongside each other after Brisbane meeting' . news.com.au, 7 August, viewed 30 September 2010, <http://www.news.com.au/features/federal-election/ gillard-and-rudd-wont-campaign-alongside-each-other-after-brisbanemeeting/story-fn5taogy-1225902429876>

Bourke, Latika. 2010. 'Rooty Hill beats global pop culture'. Sydney Morning Herald, 13 August, viewed 13 August 2010, <http://www.smh.com.au/ federal-election/rooty-hill-beats-global-pop-culture-20100813-121u0. html?utm_source=twitterfeed\&utm_medium =twitter $>$

Buchanan, Matt and Elliott, Tim. 2010. 'Red alert for Gillard fans'. Sydney Morning Herald, 5 July, viewed 6 July 2010, <http://www.smh.com.au/ national/the-diary/red-alert-for-gillard-fans-20100704-zvy2.html>

Bruns, Axel. 2003. 'Gatewatching, not gatekeeping: collaborative online news'. Media International Australia Incorporating Culture and Policy 107: 31-44.

Cahill, James and Ward, Ian. 2007. 'Old and new media: blogs in the third age of political communication'. Australian Journal of Communication 34(3): 1-21.

CeBIT. 2010. 'Labor gears up for Australia's first digital election'. CeBIT Australia, 15 July, viewed 17 July 2010, <http://www.cebit.com.au/news/ government/Labor_gears_up_for_Australias_first_digital_election >

Chen, Peter John. 2005. 'e-lection 2004? New media and the campaign'. In Marian Simms and John Warhurst (eds), Mortgage Nation: The Australian federal election 2004. Perth: API Network, 129-135.

Chen, Peter John. 2008. 'Australian political parties' use of YouTube 2007'. Communication, Politics \& Culture 41(1): 114-148.

Chen, Peter John. 2010. Online campaigning in Australia 2004-2010. Paper presented at the Elections, Campaigning and Citizens Online Workshop, 1516 October, Oxford Internet Institute, Oxford. 
Chen, Peter John and Vromen, Ariadne. 2010. Political web content consumption in the 2010 Australian election. Paper presented at Double Vision: Biennial Australian Studies Conference, 25-26 November, University of Sydney, Sydney.

Chen, Peter John and Walsh, Lucas. 2010. 'E-Election 2007? Political competition online'. Australian Cultural History 28(1): 47-54.

Counihan, Bella. 2010. 'Government tries to net votes in Howard's domain'. Sydney Morning Herald, 4 May, viewed 7 May 2010, <http://www.smh. com.au/opinion/politics/government-tries-to-net-votes-in-howards-domain20100504-u4im.html>

Esser, Frank and Spanier, Bernd. 2005. 'News management as news'. Journal of Political Marketing 4(4): 27-57.

Flew, Terry. 2008. 'Not yet the Internet election: online media, political commentary and the 2007 Australian federal election'. Media International Australia 126: 5-13.

Gibson, Rachel and Ward, Stephen. 2002. 'Virtual campaigning: Australian parties and the impact of the Internet'. Australian Journal of Political Science 37(1): 99-129.

Goot, Murray. 2008. 'Is the news on the Internet different? Leaders, frontbenchers and other candidates in the 2007 Australian election'. Australian Journal of Political Science 43(1): 99-110.

Gordon, Josh. 2010. 'Pollies all atwitter as rapid-fire ads take cheap shots'. Sydney Morning Herald, 20 June, viewed 21 June 2010, <http://www.smh. com.au/technology/technology-news/pollies-all-atwitter-as-rapidfire-adstake-cheap-shots-20100619-ynzq.html>

Gould, Philip. 1999. The Unfinished Revolution: How the modernisers saved the Labour Party. London: Abacus.

Grant, Will, Moon, Brenda and Busby Grant, Janie. 2010. 'Digital dialogue? Australian politicians' use of the social network tool Twitter'. Australian Journal of Political Science 45(4): 579-604.

Griffiths, Mary. 2010. 'Decidedly not in Sturt'. Sydney Morning Herald, 20 August, viewed 20 August 2010, <http://www.smh.com.au/opinion/ politics/decidedly-not-in-sturt-20100820-138iy.html>

Guselli, Lachlan. 2010. 'Gillard v Abbott: who's winning on Facebook?'. SBS, 21 July, viewed 23 July 2010, <http://www.sbs.com.au/news/article/1306017/ Gillard-v-Abbott---who-s-winning-in-social-media--> 
Hindman, Matthew, Tsioutsiouliklis, Kostas and Johnson, Judy A. 2003. 'Googlearchy': how a few heavily linked sites dominate politics on the web. Paper presented at the Annual Meeting of the Midwest Political Science Association, 31 March, Chicago.

Howden, Saffron. 2010. 'Libs' Google-ad blitz sparks complaints'. Sydney Morning Herald, 9 August, viewed 10 August 2010, <http://www.smh.com. au/technology/technology-news/libs-googlead-blitz-sparks-complaints20100809-11tpl.html>

Jericho, Greg. 2010. 'Spartacus no more'. Grog's Gamut, 27 September, viewed 27 September 2010, <http://grogsgamut.blogspot.com/2010/09/spartacusno-more.html>

Kwek, Glenda. 2010a. 'Operation Phoney Tony: ALP uses Twitter to target Opposition Leader'. Sydney Morning Herald, 28 May, viewed 29 May 2010, <http://www.smh.com.au/technology/technology-news/operationphoney-tony-alp-uses-twitter-to-target-opposition-leader-20100528-wkuf. html?autostart $=1>$

Kwek, Glenda. 2010b. 'Abbott v Gillard at Rooty Hill: Galaxy to investigate'. Sydney Morning Herald, 12 August, viewed 3 September 2010, <http:// www.smh.com.au/federal-election/abbott-v-gillard-at-rooty-hill-galaxy-toinvestigate-20100812-1206t.html>

Lees-Marshment, Jennifer. 2001. Political Marketing and British Political Parties. Manchester: Manchester University Press.

Lowry, Rich. 2003. Legacy: Paying the price for the Clinton years. Washington, DC: Regnery.

Marichal, Jose. 2010. Political Facebook groups: micro-activism and the digital front stage. Paper presented at Internet, Politics, Policy 2010: An Impact Assessment, 16-17 September, Oxford Internet Institute, Oxford.

Meade, Amanda. 2010. 'New media has the press gallery all a Twitter'. The Australian, 26 June, viewed 28 June 2010, <http://www.theaustralian. com.au/politics/new-media-has-the-press-gallery-all-a-twitter/storye6frgczf-1225884488511>

Marks, Kathy. 2010. 'Exclamation politics'. The Monthly, October.

Mutz, Dianna. 1995. 'Effects of horse-race coverage on campaign coffers: strategic contributing in presidential primaries'. The Journal of Politics 57: 1015-42. 
Norris, Pippa. 2000. A Virtuous Circle: Political communications in postindustrial societies. Cambridge: Cambridge University Press.

Novak, Lauren and Kenny, Mark. 2010. 'Liberals' battle plan to win key marginal seats'. Adelaide Now, 28 May, viewed 28 May 2010, <http://www. adelaidenow.com.au/news/south-australia/liberals-battle-plan-to-win-keymarginal-seats/story-e6frea83-1225872263008>

Sanders, Karen. 2009. Communicating Politics in the Twenty-First Century. Basingstoke, UK: Palgrave Macmillan.

Small, Tamara. 2008. 'Equal access, unequal success - major and minor Canadian parties on the net'. Party Politics 14(1): 51-70.

Tovey, Josephine. 2010. 'Being a first will not get Gillard off the hook'. Sydney Morning Herald, 25 June, viewed 25 June 2010, <http://www.smh.com.au/ opinion/politics/being-a-first-will-not-get-gillard-off-the-hook-20100624z3br.html>

Vromen, Ariadne. 2008. 'Political change and the Internet in Australia: introducing GetUp'. In Tapio Häyhtiö and Jarmo Rinne (eds), Net Working/ Networking: Politics on the Internet. Tampere, Finland: Tampere University Press.

Wilson, Jason. 2010. Twitter post, 11 August, viewed 3 September 2010, $<$ http://twitter.com/jason_a_w/status/20871862706> 